\title{
Economische aspecten en relaties van omliggende gebieden met het stedelijk netwerk van de Vlaamse Ruit
}

\author{
Citation for published version (APA):
}

Houvenaghel, S., Vanhaverbeke, W. P. M., David, P. A., Stalenhoef, G., \& Van Hoye, E. (1997).

Economische aspecten en relaties van omliggende gebieden met het stedelijk netwerk van de Vlaamse Ruit. NIBOR, Netherlands Institute of Business Organization and Strategy Research. NIBOR Research Memorandum No. 06 https://doi.org/10.26481/umanib.1997006

Document status and date:

Published: 01/01/1997

DOI:

10.26481/umanib.1997006

Document Version:

Publisher's PDF, also known as Version of record

\section{Please check the document version of this publication:}

- A submitted manuscript is the version of the article upon submission and before peer-review. There can be important differences between the submitted version and the official published version of record. People interested in the research are advised to contact the author for the final version of the publication, or visit the DOI to the publisher's website.

- The final author version and the galley proof are versions of the publication after peer review.

- The final published version features the final layout of the paper including the volume, issue and page numbers.

Link to publication

\footnotetext{
General rights rights.

- You may freely distribute the URL identifying the publication in the public portal. please follow below link for the End User Agreement:

www.umlib.nl/taverne-license

Take down policy

If you believe that this document breaches copyright please contact us at:

repository@maastrichtuniversity.nl

providing details and we will investigate your claim.
}

Copyright and moral rights for the publications made accessible in the public portal are retained by the authors and/or other copyright owners and it is a condition of accessing publications that users recognise and abide by the legal requirements associated with these

- Users may download and print one copy of any publication from the public portal for the purpose of private study or research.

- You may not further distribute the material or use it for any profit-making activity or commercial gain

If the publication is distributed under the terms of Article $25 \mathrm{fa}$ of the Dutch Copyright Act, indicated by the "Taverne" license above, 
Economische aspecten en relaties van omliggende gebieden met het stedelijk netwerk van de Vlaamse Ruit

S. Houvenaghel \& W. Vanhaverbeke

$\mathrm{NIBOR} / \mathrm{RM} / 97 / 06$

http://www.unimaas.nl/ document/fdewb.htm

J.E.Lit. code: 018

$n i b o r$

Netherlands Institute of

Business Organization

and Strategy Research

University of Maastricht

Faculty of Economics and Business Administration

P.O. Box 616

6200 MD Maastricht

The Netherlands

Phone: ++31 43 - 3883805 


\title{
Fax : :++3143- 3258495 \\ ECONOMISCHE ASPECTEN EN RELATIES VAN OMLIGGENDE GEBIEDEN MET HET STEDELIJK NETWERK VAN DE VLAAMSE RUIT
}

\author{
Sofie Houvenaghel en Wim Vanhaverbeke* \\ m.m.v. Peter David, Gerard Stalenhoef, Elke Van Hoye \\ Vlaamse Gemeenschap, AROHM, Afdeling Ruimtelijke Planning \\ Zandstraat 3, 1000 Brussel, België \\ (*) Nibor, Universiteit Maastricht \\ Postbus 616, 6200 MD Maastricht, Nederland
}

\begin{abstract}
SAMENVATTING
In het huidig ontwerp Ruimtelijk Structuurplan Vlaanderen (RSV) wordt het gebied tussen Brussel, Gent, Antwerpen en Leuven aangeduid als een stedelijk netwerk op internationaal niveau. Teneinde uitvoering te kunnen geven aan het RSV werd dit stedelijk netwerk nader onderzocht. In een eerste deel van het onderzoek werd gezocht naar een morfologische en functionele basis voor de Vlaamse Ruit. In dit artikel wordt meer in het bijzonder ingegaan op het economisch luik van dit onderzoek. Daarna wordt ook aangegeven dat het ontwikkelen en versterken van een stedelijk netwerk op internationaal niveau ook voor de rest van Vlaanderen een meerwaarde kan opleveren.
\end{abstract}

\section{STELLINGEN}

1. Op basis van analytisch onderzoek kan aangetoond worden dat er momenteel reeds een economische basis bestaat om van een Vlaamse Ruit als stedelijk netwerk op internationaal niveau te spreken.

2. Een specifiek beleid voor de Vlaamse Ruit dringt zich op. Uit recente cijfergegevens blijkt immers dat de Vlaamse Ruit aan economische slagkracht verliest t.o.v. de rest van Vlaanderen. Indien dit specifiek beleid afwezig blijft zal de Vlaamse Ruit nooit kunnen uitgroeien tot een volwaardig netwerk op internationaal niveau.

3. Een goed functionerend stedelijk netwerk als de Vlaamse Ruit levert ook meerwaarden voor andere gebieden in Vlaanderen. De belangrijkste meerwaarden zijn het aanbod van een ruime waaier van gespecialiseerde dienstverlening en de poortfunctie naar de rest van de wereld.

\section{Inleiding}

Het sterk verstedelijkte gebied tussen Brussel, Gent, Antwerpen en Leuven wordt in het ontwerp RSV aangeduid als een stedelijk netwerk, een complementair en samenhangend geheel van stedelijke gebieden en van structuurbepalende elementen van het buitengebied, verbonden door infrastructuren (wegen, spoorwegen, kanalen, ...).

Door de aard van het gebied, met o.a. een sterke concentratie van drie grootstedelijke gebieden (tevens motor van economische ontwikkeling), van internationale poorten als zeehavens, de internationale luchthaven en HSTstations, belangrijke universiteiten en hoogwaardige diensten beschikt de Vlaamse Ruit over de troeven om als stedelijk netwerk op Europees niveau de concurrentie aan te gaan met gelijkaardige ontwikkelingen in het buitenland (Randstad, Mainz-Ruhrgebied, ...). Daartoe dient het gebied beleidsmatig als één geheel benaderd te worden. Hierdoor kunnen de (embryonale) potenties van dit gebied versterkt worden en selectief worden ingevuld.

\section{Bestaande economische basis voor een stedelijk netwerk op internationaal niveau}

Aggregatie van economische cijfergegevens op het niveau van de Vlaamse Ruit toont aan dat de Vlaamse Ruit 'iets anders' is dan de rest van Vlaanderen. Heel wat activiteiten op het internationale niveau zijn geconcentreerd in dit gebied. De Vlaamse Ruit bevat slechts $22 \%$ van de oppervlakte en $48 \%$ van de bevolking van Vlaanderen 
en het Brussels Hoofdstedelijk Gebied samen, maar de economische waarde van dit stedelijk netwerk is ontzettend groot. Er dient vermeld te worden dat bij de analyse steeds de gegevens van Brussel werden opgenomen.

\section{a) Sterke concentratie van poorten op Europa en de wereld}

In het gebied bevinden zich - op zeer korte afstand van elkaar - enkele belangrijke poorten: zo is de luchthaven van Zaventem een belangrijke draaischijf voor Europees luchtverkeer; de zeehaven Antwerpen neemt de 5e plaats in op de lijst van de wereldhavens en heeft een hinterland dat vrijwel heel centraal Europa beslaat; de zeehaven van Gent heeft een hinterland dat vooral op Frankrijk geörienteerd is, de HST-stations Brussel en Antwerpen kunnen uitgroeien tot belangrijke internationale poorten. Deze knooppunten, waar internationale goederen- en personenstromen samenkomen, zijn tevens concentratiegebieden voor economische activiteiten met internationale oorsprong en bestemming.

\section{b) Concentratie van nationale en internationale organisaties}

Brussel is het politieke centum van Europa, België, Vlaanderen en het Brussels Hoofdstedelijk Gewest. Daarnaast is Brussel de zetel van talrijke internationale organisaties zoals de Benelux, de NAVO, de WEU, honderden gouvernementele en duizenden niet-gouvernementele organisaties.

Deze concentratie van politieke macht oefent ook een grote aantrekkingskracht uit op bedrijven. In Brussel bevinden zich een duizendtal buitenlandse privé-organisaties. Brussel is ook een belangrijk financieel en congrescentrum (3e van de wereld).

Op basis van Trends gegevens (1996) blijkt dat 17.400 van de 30.000 grootste bedrijven in België hun maatschappelijke zetel in de Vlaamse Ruit gevestigd hebben. Van 100 grootste bedrijven in Vlaanderen, zijn er 79 gevestigd in de Vlaamse Ruit.

\section{c) Concentratie van werkgelegenheid}

Uit deelstudies ter voorbereiding van het $\mathrm{RSV}^{1}$ blijkt dat de economische activiteiten in Vlaanderen momenteel nog sterk geconcentreerd zijn in de stedelijke gebieden. De Vlaamse Ruit is het Vlaams stedelijk kerngebied in Vlaanderen en vertoont dus een sterke concentratie aan werkgelegenheid. Op basis van de RSZ en RSVZ gegevens van 1994 kan gesteld worden dat 58\% van de werkgelegenheid in Vlaanderen (met inbegrip van Brussel) zich in dit gebied bevindt (t.o.v. 48\% van de bevolking). Binnen het stedelijk netwerk valt de hoge concentratie op in de stedelijke gebieden (92\%). Het gros hiervan is gelokaliseerd in de grootstedelijke gebieden, de trekkers van de economie $(76 \%)$. Het belang van de regionaalstedelijke gebieden en kleinstedelijke gebieden (resp. 10\% en 6\%) is veel minder uitgesproken.

Wat betreft de aard van de tewerkstelling, onderscheidt de Vlaamse Ruit zich duidelijk van de rest van Vlaanderen (zie tabel 1). Het gebied vertoont een sterke specialisatie in tertiaire sectoren als internationale organisaties, hoger onderwijs, onderzoek en ontwikkeling, bank- en verzekeringen, diensten aan bedrijven, immobiliën, groothandel en de vrije tijdssector. Belangrijke secundaire sectoren zijn de chemie en de transportmiddelenindustrie $^{2}$.

Tabel 1: Hoogste specialisatie-coëfficiënten sectorale tewerkstelling Vlaamse Ruit, 1991

\begin{tabular}{|l|c|c|}
\hline Sector & Vlaamse Ruit & $\begin{array}{l}\text { Vlaanderen buiten } \\
\text { Vlaamse Ruit }\end{array}$ \\
\hline & & 0.25 \\
Internationale organisaties & 1.54 & 0.42 \\
Hoger onderwijs, onderzoek en ontwikkeling & 1.42 & 0.46 \\
Bank- en verzekeringssector & 1.39 & 0.60 \\
Bedrijfsgerichte dienstverlenende sector & 1.29 & 0.63 \\
Amusementssector (vrije tijd) & 1.27 & 0.70 \\
Immobiliënsector & 1.22 & 0.75 \\
Groothandel & 1.18 & 0.76 \\
Chemie & 1.17 & 0.78 \\
Vervoersector & 1.16 &
\end{tabular}




\begin{tabular}{|l|c|c|}
\hline Communicatiesector & 1.14 & 0.80 \\
\hline
\end{tabular}

Bron: Meuris en Jurriëns (1996)

\section{d) Netwerk met een zeer hoge toegevoegde waarde}

Van de totale toegevoegde waarde die in Vlaanderen (met inbegrip van Brussel) gecreëerd wordt, wordt $71 \%$ 'toegevoegd' in de Vlaamse Ruit. De concentratie in de stedelijke gebieden is zeer groot: $95 \%$, waarvan het leeuwenaandeel in de grootstedelijke gebieden $(86 \%)^{3}$. Statistisch kan aangetoond worden dat het vooral parameters zijn als de productiviteit per bedrijf en de productiviteit per werknemer die significant verschillen tussen gemeenten in de Vlaamse Ruit en deze erbuiten. Verder onderzoek moet uitwijzen of het verschil in arbeidsproductiviteit tussen de Vlaamse Ruit en de rest van Vlaanderen te maken heeft met het feit dat de bedrijven in de Vlaamse Ruit gemiddeld groter zijn.

\section{e) Een sterk aanbod aan hoog opgeleide bevolking}

Alle grote universiteiten van Vlaanderen bevinden zich in de Vlaamse Ruit. In het zog van deze universiteiten ontwikkelen zich tal van spin-offs of komen er zich allerhande high-tech bedrijven vestigen, met hoogwaardige toepassingen van het wetenschappelijk onderzoek in de bedrijfswereld.

De bevolking in de Vlaamse Ruit heeft gemiddeld ook een hoger opleidingsniveau. Op basis van de volkstellingsgegevens van 1991 kan aangetoond worden dat 62\% van het aantal afgestudeerden met een universitair of gelijkgesteld diploma in de Vlaamse Ruit woont (t.o.v. 48\% van de bevolking). Deze categorie woont vooral in de stedelijke gebieden van de Vlaamse Ruit (vooral dan in de residientiële gemeenten aan de rand van de stedelijke gebieden).

\section{Aanzet voor complementaire ontwikkeling tussen de stedelijke gebieden in het netwerk}

Algemeen wordt gesteld dat een stedelijk netwerk samenhangend zal functioneren als de verschillende stedelijke componenten, die er deel van uitmaken, elkaar aanvullen. Er moet m.a.w. sprake zijn van een zekere taakverdeling of complementaire ontwikkeling.

Op het vlak van de werkgelegenheid evolueren de grootsteden naar een zekere complementariteit. Vaak blijken de activiteiten van de poorten hiervoor bepalend te zijn. Antwerpen en Gent kennen relatief gezien een grote werkgelegenheid in de industrie (o.a. impact van de zeehavens): Antwerpen beschikt over volledige havenfaciliteiten (opslag- en distributiefunctie, handelsfunctie, industriële functie met specifieke specialisatie in petrochemische industrie), Gent vervult een rol als industriële haven (met specialisatie in staalbewerking en -verwerking). De regio Zaventem/Machelen/Vilvoorde speelt een belangrijke rol in de luchthavengebonden bedrijvigheid. Brussel kent vooral een grote tewerkstelling in de administratieve en fincanciële sector.

Deze complementariteit uit zich ook in de lokatie van maatschappelijke zetels: in Brussel bevinden zich vooral zetels van (hoogwaardige) dienstverlening en luchthavengebonden activiteiten; in Antwerpen en Gent de zetels van bedrijven met havengebonden activiteiten. 
Ook op het vlak van het hoger onderwijs ziet men duidelijke complementariteiten opduiken. Door de toenemende complexiteit en kosten van het wetenschappelijk onderzoek dienen universiteiten en onderzoekslaboratoria zich te specialiseren op heel specifieke technologieën. Iedere universiteit heeft nu haar centers of excellence in specifieke onderzoeksdomeinen. Er bestaan zelfs programma's tussen de universiteiten om deze know-how op elkaar af te stemmen (zie K.U.Leuven en de U.Gent voor de microelectronica en de U.Gent voor biotechnologie).

Tussen de regionaalstedelijke en kleinstedelijke gebieden is de complementariteit niet zo eenvoudig te duiden. Belangrijker evenwel is de duidelijke hierarchie tussen de grootstedelijke gebieden enerzijds en de regionaalstedelijke en kleinstedelijke gebieden anderzijds. Dit kan ondermeer geïllustreerd worden via gegevens over het woonwerkverkeer; Brussel en in mindere mate Antwerpen zijn centrale tewerkstellingspolen voor pendelaars uit andere regio's. Brussel-Antwerpen is de enige as waar sprake is van een twee richtingenverkeer - zij het zwaar asymmetrisch. Brussel vormt een tewerkstellingspool voor alle nabijgelegen regionaalstedelijke en kleinstedelijke gebieden. Antwerpen is vooral een tewerkstellingspool voor St-Niklaas en Mechelen. M.a.w., uitgaande van pendelgegevens kan men stellen dat de grootstedelijke gebieden economische attractiepolen zijn voor de omliggende verstedelijkte gebieden in en rond de Vlaamse Ruit. Verder onderzoek uitgaande van goederen- en informatieverkeer moet uitwijzen of die hiërachische opbouw effectief bestaat. 


\section{Een specifiek beleid voor de Vlaamse Ruit dringt zich op}

De hierboven geschetste potenties van het gebied blijken zich niet op een spontane wijze te ontwikkelen tot effectieve meerwaarden. Uit recente cijfergegevens blijkt immers dat de Vlaamse Ruit op economisch vlak aan slagkracht verliest t.o.v. de rest van Vlaanderen. Zo groeit de tewerkstelling in de Vlaamse Ruit trager dan in de rest van Vlaanderen (resp. + $3.1 \%$ en $+13.7 \%$ in de periode 1981-1991). Zelfs voor die sectoren waarin de Vlaamse Ruit een aanzienlijk aandeel heeft en waarin het gespecialiseerd is, neemt de tewerkstelling minder sterk toe dan in andere gebieden. Bovendien is er binnen de Vlaamse Ruit een erosie van de economische slagkracht van de grootstedelijke gebieden t.v.v. regionaal- en kleinstedelijke gebieden en het buitengebied (zie tabel 2).

Tabel 2: Evolutie in het aandeel in de tewerkstelling tussen 1981-1991 in de Vlaamse Ruit voor de sectoren waarin de Vlaamse Ruit gespecialiseerd is.

\begin{tabular}{|l|c|c|c|c|c|}
\hline Sector & grootst & regionaalst & kleinst (str) & kleinst (prov) & buitengebied \\
\hline Chemie & & & & & \\
Transportmiddelen & -- & ++ & 0 & 0 & ++ \\
Groothandel & -- & 0 & ++ & - & - \\
Bedrijfsg. Diensten & -- & ++ & + & + & ++ \\
Bank en verzekering & - & + & + & 0 & + \\
Vervoer & -- & - & 0 & 0 & + \\
& & & + & + & ++ \\
\hline
\end{tabular}

Bron: Meuris en Jurriëns (1996)

Zonder een specifiek beleid t.a.v. de Vlaamse Ruit zal de ruimte, die momenteel reeds zwaar onder druk staat, verder dichtslibben: er zullen zich economische activiteiten vestigen die de potenties van het gebied niet optimaal benutten.

Daarom dient een beleid te worden uitgestippeld dat de econoomische potenties van het gebied op een selectieve wijze invult en erop gericht is de externe bereikbaarheid en het intern functioneren (vb.congestieproblemen) te verbeteren. Het concept Vlaamse Ruit wordt dan een strategisch concept waarbij binnen het geschetste kader strategische projecten gerealiseerd worden die bijdragen tot het beter functioneren van het stedelijk netwerk op internationaal niveau.

\section{Belang van de Vlaamse Ruit voor de rest van Vlaanderen}

In deze sectie bespreken we het belang van de Vlaamse Ruit voor de economie in de rest van Vlaanderen. In wat volgt vallen we vaak terug op het voorbeeld van Zuid West-Vlaanderen (120 km van Brussel) omdat de relatie tussen de economie in de Vlaamse Ruit en de streekeconomie al bestudeerd is in een andere studie ${ }^{4}$. Zuid West-Vlaanderen is een industriële pool die vooral gekenmerkt wordt door endogene groei en door een snelle inhaalbeweging inzake tertiarisering. Dit laatste is dan weer een direct gevolg van de kennisintensivering van de industriële activiteiten. 


\section{Productiegebonden diensten}

In tegenstelling met vele andere industriële regio's in Europa is een industriële regio als Zuid West-Vlaanderen er tot op heden in geslaagd om de industriële tewerkstelling te stabiliseren terwijl heel wat jobs in de tertiaire sector - via hulpdiensten en ondersteunende diensten indirect bijdragen tot de locale industriële productie: De relatief goed gestructureerde industriële kern blijft de locale (groei in de) welvaart schragen.

In tabel 3 wordt geïllustreerd hoe de internationale competitiviteit van drie industriële sectoren die sterk geconcentreerd zijn in Zuid West-Vlaanderen verbonden is aan het bestaan van lokale competenties samen met competenties die betrokken worden uit andere (buitenlands Deze gegevens houden een lichte overschatting van de werkelijke situatie in omdat de Nationale Bank van België de gegevens voor toegevoegde waarde toewijst aan de plaats van de zetel van het

Tabel 3: De origine van competitieve voordelen in drie industrieën

\begin{tabular}{|c|c|c|}
\hline \multicolumn{2}{|c|}{ Specifieke factoren } & \multirow[t]{2}{*}{ Generieke factoren } \\
\hline Binnen de regio & Buiten de regio & \\
\hline \multicolumn{3}{|l|}{ Diepvriesgroenten industrie } \\
\hline $\begin{array}{l}\text { - Ondernemerscultuur } \\
\text { - Familiekapitaal } \\
\text { - Historisch toeval } \\
\text { - Kleine teeltoppervlakten in } \\
\text { West-Vlaanderen } \\
\text { - Nabijheid van sommige } \\
\text { landbouwproducten (bloemkool) } \\
\text { - Diepvriesinstallaties (service) }\end{array}$ & $\begin{array}{l}\text { - Machinebouwers Nederland } \\
\text { (technologisch geavanceerd) } \\
\text { - Gespecialiseerd transport Zuid- } \\
\text { Nederland } \\
\text { - Landbouwproducten : Land- } \\
\text { bouw in Nederland : toevoer via } \\
\text { havens }\end{array}$ & $\begin{array}{l}\text {-Teelttechnische kennisinfra- } \\
\text { structuur in de regio } \\
\text { - Regionale machinebouwers } \\
\text { (achterstand technologie) } \\
\text { - Hallen Roeselare } \\
\text { - Administratieve en financiële } \\
\text { diensten } \\
\text { - Computer en software }\end{array}$ \\
\hline \multicolumn{3}{|l|}{ Kunststofverwerkende industrie } \\
\hline $\begin{array}{l}\text { - Ondernemerscultuur } \\
\text { - Familiekapitaal } \\
\text { - Historisch toeval } \\
\text { - Klantgerichtheid / flexibele } \\
\text { automatisatie } \\
\text { - Sociaal klimaat } \\
\text { - Matrijzenbouwers (communica- } \\
\text { tie bij engineering, snelheid) } \\
\text { - Technologische ondersteuning } \\
\text { - Af- en bewerkingsactiviteiten } \\
\text { (communicatie; klantgerichtheid) }\end{array}$ & $\begin{array}{l}\text { - Grondstofleveranciers } \\
\text { - Machinebouwers } \\
\text { - Logistiek en warehousing } \\
\text { - Opleiding }\end{array}$ & $\begin{array}{l}\text { - Administratieve en financiële } \\
\text { diensten } \\
\text { - Computer en software } \\
\text { - Juridische diensten }\end{array}$ \\
\hline \multicolumn{3}{|l|}{ Textielsector } \\
\hline $\begin{array}{l}\text { - Ondernemerscultuur } \\
\text { - (Familiekapitaal) } \\
\text { - Geschoolde arbeid (vakman- } \\
\text { schap) } \\
\text { - Besturingssystemen (service) } \\
\text { - Electronisch gestuurde machines } \\
\text { - Bepaalde toeleveranciers } \\
\text { (spinnerijen) }\end{array}$ & $\begin{array}{l}\text { - CAD-CAM leveranciers } \\
\text { - Labo-apparatuur } \\
\text { - Mechanische machines } \\
\text { - Toeleveranciers standaard- } \\
\text { producten } \\
\text { - Productontwikkeling }\end{array}$ & $\begin{array}{l}\text { - Administratieve en financiële } \\
\text { diensten } \\
\text { - Juridische diensten } \\
\text { - Generieke hard- en software }\end{array}$ \\
\hline
\end{tabular}


Bron: Vanhaverbeke (1996)

bedrijf. De produktie van sommige bedrijven met een zetel in de Vlaamse Ruit heeft plaats buiten de Vlaamse Ruit. Dezelfde redenering geldt voor grootstedelijke gebieden binnen de regio's. De geografische concentratie wijst op het feit dat de bedrijfseconomische competitiviteit ten dele stoelt op de locale economische situatie. Maar de locale economische omgeving kan slechts een deel van het succes verklaren : Zonder efficiënt gebruik te maken van economische competenties in andere regio's zou het internationaal succes van deze bedrijfstakken vlug verdwijnen.

Deze tabel leert ons heel wat over de kritische succesfactoren die de basis vormen van de internationale competitiviteit van geografisch geconcentreerde clusters van bedrijven:

- Het eerste wat opvalt is de brede waaier van locale succesfactoren. Dit is deels het gevolg van de selectie: de drie sectoren vertonen een duidelijke geografische concentratie waardoor het belang van de locale factoren meer uitgesproken is dan in de meeste andere sectoren.

- Bij de locale factoren zijn er een aantal die telkens terugkeren : sociale verhoudingen, ondernemerschap, familiekapitaal, flexibiliteit, klantgerichtheid, snelheid. Dit wijst erop dat de competitiviteit in verschillende (clusters) van industrieën gebaseerd is op een aantal karakteristieken van de socio-economische omgeving. Andere locale succesfactoren zijn dan weer specifiek voor een bepaalde bedrijfstak.

- Verschillende belangrijke inputfactoren kunnen in principe zowel bij locale toeleveranciers als in andere regio's gekocht worden. Een mooi voorbeeld zijn de productiemachines voor de diepvriesgroentenindustrie: Er bestaan locale machinebouwers, maar buitenlandse machinebouwers krijgen steeds meer de voorkeur omwille van hun technologische voorsprong. Technologie gedreven concurrentie komt ook naar voor in de kunststofverwerkende industrie.

- Uit de lijst van streekgebonden succesfactoren blijkt dat de rol van de kenniseconomie steeds belangrijker wordt.

Kortom, de concurrentiële positie van bedrijven gelegen buiten de Vlaamse Ruit wordt bepaald door een combinatie van locale competenties en competenties die betrokken worden uit andere regio's. De werking van de meeste industriële bedrijven is ingebed is in de nationale en Europese economie. Slechts een kleine fractie van de toegeleverde goederen en diensten wordt betrokken uit de streek zelf. De meeste ervan worden verzorgd door andere Vlaamse / Belgische en internationale bedrijven.

Er zijn natuurlijk ook andere diensten waarop de industriële bedrijven een beroep doen, maar dit zijn standaarddiensten waar geen concurrentieel voordeel uit te halen valt of ze zijn van marginaal belang voor de bedrijfsvoering (vb. industriële reiniging).

Sommige kritische succesfactoren en de meeste van de standaarddiensten zijn gesitueerd in de Vlaamse Ruit. De haven van Gent is bijvoorbeeld erd belangrijk voor de diepvriesgroenten-industrie. De meeste generieke diensten zoals vertaalbureau's, boekhoudingskantoren, juridische en administratieve diensten, informatica-installateurs, etc... worden allamaal op efficiënte wijze betrokken uit de Vlaamse Ruit.

\section{De Vlaamse Ruit en locale infrastructurele voorzieningen ${ }^{5}$ in de rest van Vlaanderen}

In de volgende twee punten gaan we respectievelijk in op locale infrastructurele voorzieningen in de rest van Vlaanderen en de relatie die een economische pool buiten de Vlaamse Ruit kan uitbouwen t.o.v. de Vlaamse Ruit als een belangrijk en nabijgelegen stedelijke netwerk op internationaal niveau. 

Welke infrastructurele voorzieningen kunnen locaal uitgebouwd worden in een economische pool buiten de Vlaamse Ruit? Hierbij dient men kritisch na te gaan welke competenties er beter betrokken worden uit andere economische en technologische centra en welke er best locaal uitgebouwd worden tot "centers of excellence".

Een onderzoek naar locale infrastructurele voorzieningen dient te starten vanuit de specifieke noden van bedrijven met een locale aanwezigheid. Eens men de specifieke noden van de bedrijven kent dient men na te gaan of de nodige infrastructurele voorzieningen geen grootstedelijk draagvlak vereisen. Voorbeelden zijn universiteiten, hogescholen met een generieke opleiding, research laboratoria (bvb. met betrekking tot nieuwe technologieën), congres- en expositiecentra met een internationale reputatie, internationale luchthavens, enz... Wanneer blijkt dat de bedrijven uit andere regio's en landen een een meer hoogwaardige en gespecialiseerde dienstverlening kunnen verzorgen, zou een duplicatie van deze infrastructurele ondersteuning in eigen streek zonde zijn.

Heel wat gespecialiseerde inputs kan men evenwel niet betrekken uit andere regio's. Daar zijn verschillende redenen voor. Technisch geschoolde arbeidskrachten bijvoorbeeld dient men in hoofdzaak locaal op te leiden en bij te scholen omdat arbeid een weinig mobiele factor is. Kennisoverdracht van toegepaste technologische know-how bijvoorbeeld is vaak moeilijk (tacit knowledge) omdat er intensief en frequent menselijk contact nodig is om de kennis te transfereren. Dit is niet mogelijk als de afstanden te groot zijn. Er zijn dus een aantal infrastructurele voorzieningen met een strategische economische rol die locaal moeten uitgebouwd worden.

\section{(b) Het belang van een nabijgelegen stedelijk netwerk op internationaal niveau}

De Vlaamse Ruit heeft een niet geringe "aantrekkingskracht" op de andere economische polen in Vlaanderen. Gegeven de groeiende internationalisatie van de economie en het groeiend belang van stedelijke netwerken met internationale uitstraling zal deze invloed ongetwijfeld nog toenemen in de toekomst.

Het statuut van de Vlaamse Ruit als stedelijk netwerk op internationaal niveau zal dus zonder twijfel een geografische concentratie van de hedendaagse hoogwaardige economische infrastructuur met zich meebrengen en economische polen buiten de Vlaamse Ruit zullen steeds meer economische activiteiten moeten betrekken uit de Ruit.Daaronm dient ook de toegang tot deze voorzieningen vanuit de rest vanVlaanderen geoptimaliseerd te worden. Bedrijven kunnen alleen optimaal gebruik maken van de infrastructuur binnen de Vlaamse Ruit door netwerkfuncties met de Ruit en andere techno-economische centra van belang uit te bouwen, waardoor de economische competenties binnen de subregio kunnen behouden of versterkt worden. In die zin is het van groot belang dat de bedrijven efficiënt en strategisch leren omgaan met de informatie en diensten die voorhanden is in grote technoeconomische centra. Dit kan alleen door het opzetten van (inter)nationale functionele netwerken: deze netwerken vormen steeds meer mee de basis van de hedendaagse competitiviteit in industriële (ook traditionele) sectoren. In andere landen is men daarin al verder. 
In essentie dient men in gebieden buiten de Vlaamse Ruit de actieve uitbouw van dit grootstedelijk netwerk als een positief gegeven te beschouwen. Zonder een goed functionerend Vlaamse Ruit zouden bedrijven deze diensten moeten betrekken uit grootstedelijke gebieden die heel wat verder liggen waardoor de dienstverlening minder efficiënt, duurder of zelfs onmogelijk wordt. De uitbouw van een goed functionerende stedelijk netwerk zoals de Vlaamse Ruit is een conditio sine qua non opdat de ganse Vlaamse (Belgische) economie zou kunnen verder groeien.

\section{Conclusie}

Het economisch belang van de Vlaamse Ruit als stedelijk netwerk met internationale uitstraling kan moeilijk onderschat worden. Een goed functionerend stedelijk netwerk is van levensbelang voor de werking van hedendaagse geavanceerde economieën.

De Ruit heeft alle economische karakteristieken die wijzen op zo'n grootstedelijk netwerk. Op basis van analytisch onderzoek kan aangetoond worden dat er momemteel reeds een economische basis hiervoor bestaat. Binnen de Vlaamse Ruit spelen de drie stedelijke gebieden de belangrijkste rol. Brussel, Antwerpen en Gent vervullen hoofdzakelijk een complementaire economische rol en de onderlinge afhankelijkheid van de drie grootstedelijke gebieden is groot.

Terzelfdertijd constateren we een erosie van haar economische slagkracht in de periode 1981-1991. Dit wijst op een aantal problemen die ondermeer beleidsmatig moeten opgelost worden indien de Vlaamse Ruit haar internationale rol als netwerk wil waarmaken. In die zin moet er een trendbreuk gerealiseerd worden opdat de Vlaamse Ruit haar economische rol zou kunnen vervullen.

Ook voor de economie in de rest van Vlaanderen speelt de Vlaamse Ruit een belangrijke rol. De meeste bedrijven zijn ingebed in de nationale en Europese economie en slechts een kleine fractie van de toegeleverde goederen en diensten wordt betrokken uit de streek zelf. De competitiviteit van de meeste bedrijven wordt bepaald door het aantrekken van verschillende competenties uit diverse regio's in combinatie met de economische troeven van de eigen regio. De economische meerwaarde die gegenereerd wordt door de nabijheid van een grootstedelijk netwerk met internationale uitstraling kan moeilijk onderschat worden. De keerzijde van de medaille is dat verschillende grootstedelijke netwerken concurreren met elkaar voor het aantrekken van hoogwaardige economische activiteiten. Om die attractiviteit te behouden en te versterken dient er continue geïnvesteerd te worden in de infrastructurele voorzieningen binnen de Vlaamse Ruit.

In essentie dient men dus in gebieden buiten de Vlaamse Ruit de actieve uitbouw van dit grootstedelijk netwerk als een positief gegeven te beschouwen. De rest van Vlaanderen profiteert van de Vlaamse Ruit doordat een ruimere waaier van economische activiteiten en dienstverlening binnen een straal van $100 \mathrm{~km}$ beschikbaar is. Zonder een goed functionerende Vlaamse Ruit zouden bedrijven deze diensten moeten betrekken uit grootstedelijke gebieden die heel wat verder liggen waardoor de dienstverlening minder efficiënt, duurder of zelfs onmogelijk wordt.

Een economische pool buiten de Vlaamse Ruit kan maar inspelen op de infrastructuur binnen 
de Ruit wanneer gezorgd wordt voor een optimale interactie tussen de Vlaamse Ruit en de rest van Vlaanderen. In die zin dient men werk te maken van het goederen-, personen- en informatieverkeer tussen de Vlaamse Ruit en de rest van Vlaanderen. Deze eis voor een betere toegang tot infrastructurele voorzieningen in de Vlaamse Ruit houdt ook in dat locale infrastructurele voorzieningen buiten de Vlaamse Ruit complementair zijn met die binnen de Ruit.

De uitwerking van het internationaal stedelijk netwerk, de Vlaamse Ruit, maakt deel uit van de opdracht 'Uitvoering geven aan het Ruimtelijk Structuurplan Vlaanderen'. De bijdragen aan de Planologische Discussiedagen 1997 m.b.t. de Vlaamse Ruit van Peter David, Sofie Houvenaghel en Wim Vanhaverbeke, Gerard Stalenhoef en Elke Van Hoye zijn opgesteld in eigen naam en vallen uitsluitend onder de verantwoordelijkheid van de auteurs.

\section{Noten}

1. Vanhaverbeke, Wim et al. (1993); Economisch profiel van de Vlaamse Stadsgewesten, KUL-ISRO, deelproject Prognoses: sector economie, oktober, $319 \mathrm{p}$.

2. Meuris, Filip en Marije Jurriëns (1996); Vlaamse Ruit: Synthesenota, KUL - ISRO, Leuven, deceber.

3. Deze gegevens houden een lichte overschatting van de werkelijke situatie in omdat de Nationale Bank van België de gegevens voor toegevoegde waarde toewijst aan de plaats van de zetel van het bedrijf. De produktie van sommige bedrijven met een zetel in de Vlaamse Ruit heeft plaats buiten de Vlaamse Ruit. Dezelfde redenering geldt voor grootstedelijke gebieden binnen de Vlaamse Ruit.

4. Vanhaverbeke, Wim (1996); Tertiarisering in een industriële regio: Een strategische visie op en beleidsprioriteiten voor Zuid West-Vlaanderen, Kortrijk: Charter 99, 185 p.

5. Met infrastructurele voorzieningen worden hier niet alleen de klassieke infrastructurele voorzieningen bedoeld maar ook de kennis- en informatieinfrastructuur 